\title{
Air pollution records from urban lake sediments: the implications of datable, lacustrine sedimentary archives for epidemiology
}

\author{
A. T. Worsley ${ }^{1}$, A. L. Power ${ }^{1}$, C. A. Booth ${ }^{2}$, N. Richardson ${ }^{1}$, \\ P. G. Appleby ${ }^{3} \&$ C. Orton ${ }^{4}$ \\ ${ }^{1}$ Natural.Geographical and Applied Sciences, \\ Edge Hill University College, Ormskirk, Lancashire, UK \\ ${ }^{2}$ Research Institute in Advanced Technologies (RIATec), \\ The University of Wolverhampton, West Midlands, UK \\ ${ }^{3}$ Department of Mathematical Sciences, University of Liverpool, \\ Liverpool, $U K$ \\ ${ }^{4}$ Halton Primary Care Trust, Widnes, Cheshire, UK
}

\begin{abstract}
Sediment pollution records from several small, urban, man-made lakes from Merseyside and Halton (N.W. England, UK) are presented. They demonstrate that lake sediments can be used to reconstruct atmospheric pollution histories that encompass the entire Industrial Revolution (the last 250 years) in the U.K. Regionally, this was a period that saw the instigation, development and subsequent expansion of major industrial activity, such as iron and steel production, petro-chemical manufacture and power generation, followed by rises in road and air travel. Through the use of analytical techniques, such as environmental magnetism, together with ${ }^{210} \mathrm{~Pb}$ dating, urban lacustrine stratigraphic records illustrate that the types and levels of atmospheric pollution have changed temporally. The work promotes the ethos that such archives could be vital to our understanding of past, present and future relationships between human health and the environment.
\end{abstract}

Keywords: atmospheric particulate pollution, lake sediments, mineral magnetism, environmental health. 


\section{Introduction}

Epidemiologists express major concerns about relationships between atmospheric quality and human health $[1,2,3]$. The contribution of atmospheric quality to hospital admission rates, disease types and mortality rates is difficult to measure since much of the information available relies on contemporary environmental data sets (e.g. air filtration/capture) [4]. Such monitoring programmes yield information about spatial patterns, plus diurnal and seasonal variations in atmospheric quality. However, they do not reveal historical changes. Obtaining longer-term temporal records from within urban areas is vital, in order to compare them with historical community health data. Then it may be possible to examine more closely the relationship between human health, most notably respiratory diseases, and atmospheric pollution resulting from anthropogenic activity.

Lake sediments (in addition to peat and estuarine deposits) act as repositories of atmospheric and catchment-based materials, which can reveal archived environmental information [5, 6, 7]. Furthermore, they are particularly useful because, by capturing atmospheric pollutants, they retain a record of anthropogenic activity and natural change [8]. However, to date most research programmes involving temporal reconstructions, particularly atmospheric pollution, have utilised sites in remote areas, e.g. in upland locations that are often considerable distances from any potential sources of industrial output $[9,10]$.

Ongoing research by the current authors is investigating several lake sites situated within urban areas and therefore much closer to potential industrial sources of atmospheric pollutants (Figure 1). In this study, magneto-pollution stratigraphies from several sites are interrogated firstly to demonstrate that it is possible, with care, to locate urban lake sites yielding datable information and secondly, reveal whether the information can offer insights for epidemiologists.

\section{The Industrial Revolution and atmospheric pollution}

In the UK industrial activity has been at the heart of urban development for more than 200 years [11]. The major conurbations, including Merseyside (Liverpool), Greater Manchester, the Midlands (Birmingham) and Greater London owe their origins and growth to the development of major manufacturing industries, such as petro-chemicals and iron and steel, plus the concomitant need for power generation [12]. The Industrial Revolution, as it is known in the UK, began in the late eighteenth century, intensified significantly in the nineteenth century and, with advances in technology and the opening up of world markets, changed in character distinctively in the twentieth century [13, 14]. For instance, heavy industries such as petro-chemical, iron and steel manufacturing, gave way to companies producing alternative products, for example, pharmaceuticals. Alongside the development of modern technologies, together with changes in the nature of and methods used in manufacturing, has come the burgeoning of road and air travel. 

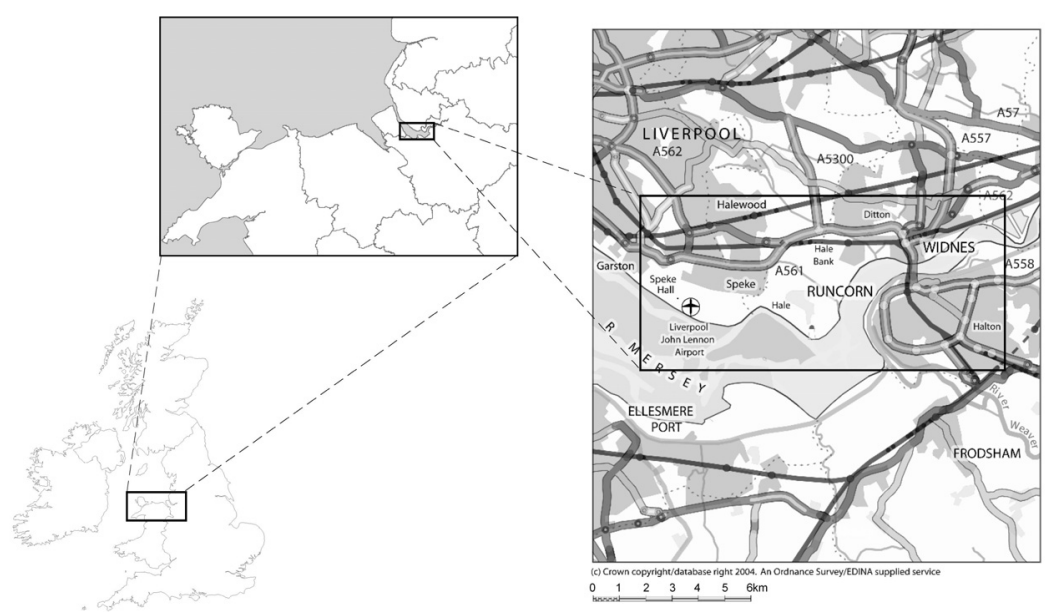

Figure 1: $\quad$ Location map of the study area in north-west England, UK.

Much is known about the nature of life in the rapidly growing urban communities during the Industrial Revolution, especially during the nineteenth century [15]. Towns growing around industrial sites were characterised by poor terraced housing, but most importantly, by large numbers of chimney stacks emitting by-products of industrial activity directly into the atmosphere, and by malodorous, dense smog, black soot and vegetation death [16].

\section{The study area}

\subsection{Merseyside and Halton}

Lake sites from within the Merseyside Conurbation and in North Cheshire are part of a large study that is investigating spatial and temporal patterns of atmospheric pollution in North-West England, UK. Specifically, the sites lie north and south of the lower Mersey Estuary, within South Liverpool and Widnes to the north of the River Mersey and Runcorn (in Halton, Cheshire) to the south (Figure 1). All the sites were identified following extensive investigations into historical documents and maps to verify their age and permanence within the landscape and to ensure that the lakes had not been disturbed by de-silting. Several of the small lakes were originally man-made agricultural ponds that have been incorporated within the expanding industrial and urban landscape over the last 250 years. Only the lake at Speke Hall (Merseyside) was constructed for other purposes including fishing [17], and subsequently subsumed into the urban and industrial expansion of Liverpool.

This region has a long and intensive industrial history. As the port of Liverpool expanded so too did the industrial sites at Widnes and Runcorn. Here, the development and growth of the chemical industry was at its greatest [18]. Production of sulphuric acid, chlorine gas, fertilisers and many other products 
led to Widnes and Runcorn being hailed as the "dirtiest, ugliest and most depressing" towns in England [11]. Indeed a writer commented " The foul gases which belched forth night and day from the many factories rot the clothes, the teeth, and, in the end, the bodies of the workers, have killed every tree and every blade of grass for miles around" [19].

Air pollution, land contamination, chemical waste went hand-in-hand with premature mortality, severe health problems among the chemical workers and their families and environmental degradation in the form of vegetation loss, most notable in parks and gardens [20]. In spite of the Alkali Acts in 1863 the region continued to emit toxic, noxious substances until World War II [21]. At the start of the twenty-first century, a more limited output still gives cause for concern among health workers with the possibility of accidental escape of pollutants remaining. Indeed, the contamination of local homes in Runcorn with HCBD (hexachlorobutadene) in 1999 made national news headlines [22].

\subsection{The lake sites}

Seven sites in South Liverpool, Widnes and Runcorn have been identified and sampled (Figure 2), but not all have been analysed yet.

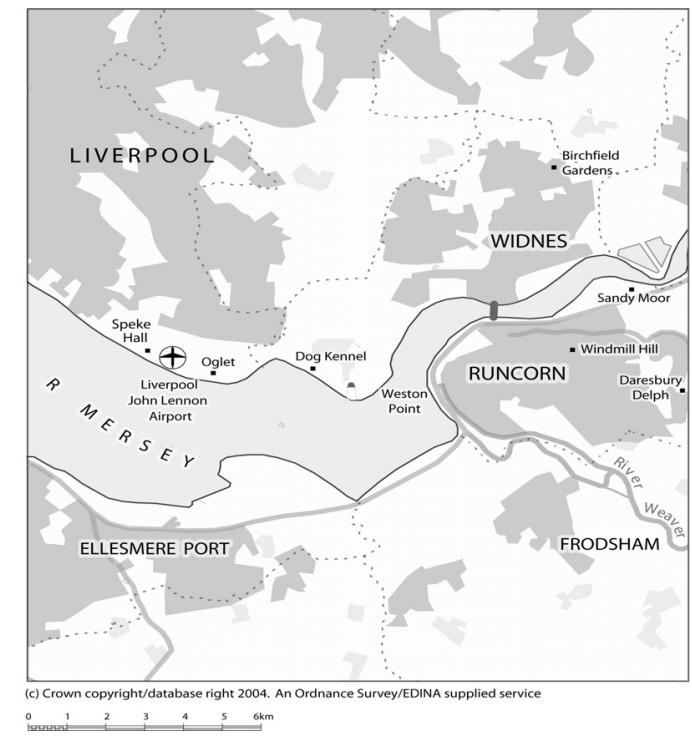

Figure 2: South Liverpool, Merseyside and Widnes/Runcorn, Halton, Cheshire.

Each lake is situated in the heart of the regional urban industrial zones. In South Merseyside, Speke Hall Lake, Oglet and Dog's Kennel ponds are adjacent to the Ford production facility, pharmaceutical and other manufacturing industries and John Lennon International Airport; in Widnes and Runcorn the Birchfield Gardens site and the ponds at Daresbury Delph, Windmill Hill and 
Sandymoor are located within urban housing zones intermingled with industrial sites, the Runcorn lakes lying east of the enormous ICI facility at Weston Point. All sites are man-made, with small catchments (catchment area $\leq$ lake area in all cases except Speke Hall Lake), so the most notable contributions to the sediment column are from atmospheric input and vegetation (e.g. surrounding trees and shrubs).

\section{Methodology}

The lakes were cored using a Gilsen hand-operated piston corer. All cores were sampled at $0.5 \mathrm{~cm}$ intervals, sediment dried at $35^{\circ} \mathrm{C}$, packed into $10 \mathrm{ml}$ plastic pots and subjected to mineral magnetic analyses (magnetic susceptibility, $\chi$, for the purposes of this paper) using a Bartington MS2 Meter [23]. A suite of additional analytical tools (XRF, SCP, SEM) has also been employed [24, 25] but these data are not presented. Dried sediment was analysed for ${ }^{210} \mathrm{~Pb},{ }^{226} \mathrm{Ra}$, ${ }^{137} \mathrm{Cs}$ and ${ }^{241} \mathrm{AM}$ at the University of Liverpool, Environmental Radioactivity Laboratory, to permit calculation of ${ }^{210} \mathrm{~Pb}$ dates using the CRS model [26].

\section{Results}

Results from Speke demonstrate it is possible to reconstruct detailed, datable pollution histories from these techniques provided they are analysed alongside documentary and other historical records for the site [27, 28]. Results from Daresbury Delph and Windmill Hill (Runcorn) are presented.

At Speke, sedimentary analyses highlight three major phases of atmospheric pollution input in the sedimentary column, which are deemed to be related closely to changes in anthropogenic activity in the region (Table 1).

Table 1: Major phases of anthropogenic activity in south Merseyside, identified in the Speke cores [27].

\begin{tabular}{|l|l|l|}
\hline Phase 3: & $\begin{array}{l}1970-2000 \\
(4.5-0 \mathrm{~cm})\end{array}$ & $\begin{array}{l}\text { Replacement of old industries, expansion of } \\
\text { road and air traffic }\end{array}$ \\
\hline Phase 2: & $\begin{array}{l}1881-1970 \\
(14.5-4.5 \mathrm{~cm})\end{array}$ & Regional expansion of industrial Merseyside \\
\hline Phase 1: & $\begin{array}{l}1700-1881 \\
(24.5-14.5 \mathrm{~cm})\end{array}$ & Early industrialisation in the Speke area \\
\hline
\end{tabular}

The dated Speke core reveals several distinctive features (a-g in Table 2; Figure 3). By comparing these features to the profiles obtained from other sites it is possible to cross correlate between both cores and sites and match events. Features (a) - (e) can be identified in cores from Windmill Hill, Daresbury Delph, and Dog's Kennel. It is highly likely that these are key regional events highlighting changes in atmospheric pollution levels across the region. 
Table 2: $\quad$ Dated features identified from the Speke analyses [27, 29].

\begin{tabular}{|c|c|c|c|}
\hline Feature & $\begin{array}{l}\text { Depth } \\
\text { (cm) }\end{array}$ & ${ }^{210} \mathrm{~Pb}$ date & Characteristic \\
\hline (a) & 1.5 & 1994 & $\begin{array}{l}\chi \text { slight decline, not similar to } \\
\text { (c) and (e) }\end{array}$ \\
\hline (b) & 2.5 & 1987 & $\chi$ rise to similar levels as $(\mathrm{d})$ \\
\hline (c) & 3.5 & 1979 & $\begin{array}{l}\chi \text { falls to similar levels to (e) } \\
\text { early } 20^{\text {th }} \text { century }\end{array}$ \\
\hline (d) & 6.5 & 1955 & $\begin{array}{l}\chi \text { high following general } \\
\text { increase from }(\mathrm{e})\end{array}$ \\
\hline (e) & 11.5 & 1912 & $\begin{array}{l}\chi \text { low change in magnetic } \\
\text { characteristics }\end{array}$ \\
\hline \multirow[t]{2}{*}{ (f) } & 14.5 & 1880 & $\chi$ high, marked peak \\
\hline & & Documented date & \\
\hline (g) & $25-27$ & c. 1640 & $\begin{array}{l}\text { Low } \chi \text { values, pre-Industrial } \\
\text { Revolution }\end{array}$ \\
\hline
\end{tabular}

Since magnetic measurements are widely acknowledged as a pollution proxy, it can therefore be inferred that where $\chi$ is high, atmospheric pollution is raised. However, a full suite of measurements to include SIRM, ARM and IRM allows a more detailed interpretation of the nature of the pollutant and is being readied for publication.

Level (g), immediately above the basement clay-lining layer (traditionally used in small anthropogenic lakes and ponds), depicts pre-Industrial Revolution levels of atmospheric pollution. This is also apparent at Daresbury Delph, Dog's Kennel and Windmill Hill. Feature (f) which occurs at Speke is interpreted as a local series of events or single episode which lasted for many years and produced high levels of atmospheric particulates from combustion. It suggests small scale but fairly concentrated local industrial activity of the kind documented for the area and characteristic of the rapid developments seen as the Industrial Revolution gained momentum. Given the sites' proximity to the expanding port of Liverpool, yet relatively easy access to tracts of woodland, it is probable that the atmospheric output derives from several small-scale industries, which used combustion processes. However, at Windmill Hill ( $\mathrm{C}$ on Figure 3 ) gaps in the down-core profile represent very high $\chi$ levels, too large display on this graph but which are interpreted as very local pollution events occurring in and around Runcorn.

By the beginning of the twentieth century atmospheric pollution levels (Speke) had fallen (feature (e)), with further rising levels to feature (d) in the 1950s. This rise is perceived to reflect the requirements of the two World Wars and the intervening expansion of specialist chemical industries in Widnes and Runcorn (1920s and 1930s). Following World War II, the recognition that 
atmospheric pollution was again exacting a heavy toll in terms of public health led to the Clean Air Acts (1956) and the effects of this is reflected by falling levels of atmospheric pollution to feature (c) in the Speke Core. Feature (b) reflects the rapid rise of road and air travel. This change is supported by Power et al [28] who reported a shift in magnetic characteristics, indicative of particulates from the internal combustion engines. Finally, feature (a), dated to 1994, sees a slight reduction in pollution levels with a subsequent rise at the uppermost level representing the start of the twenty first century.

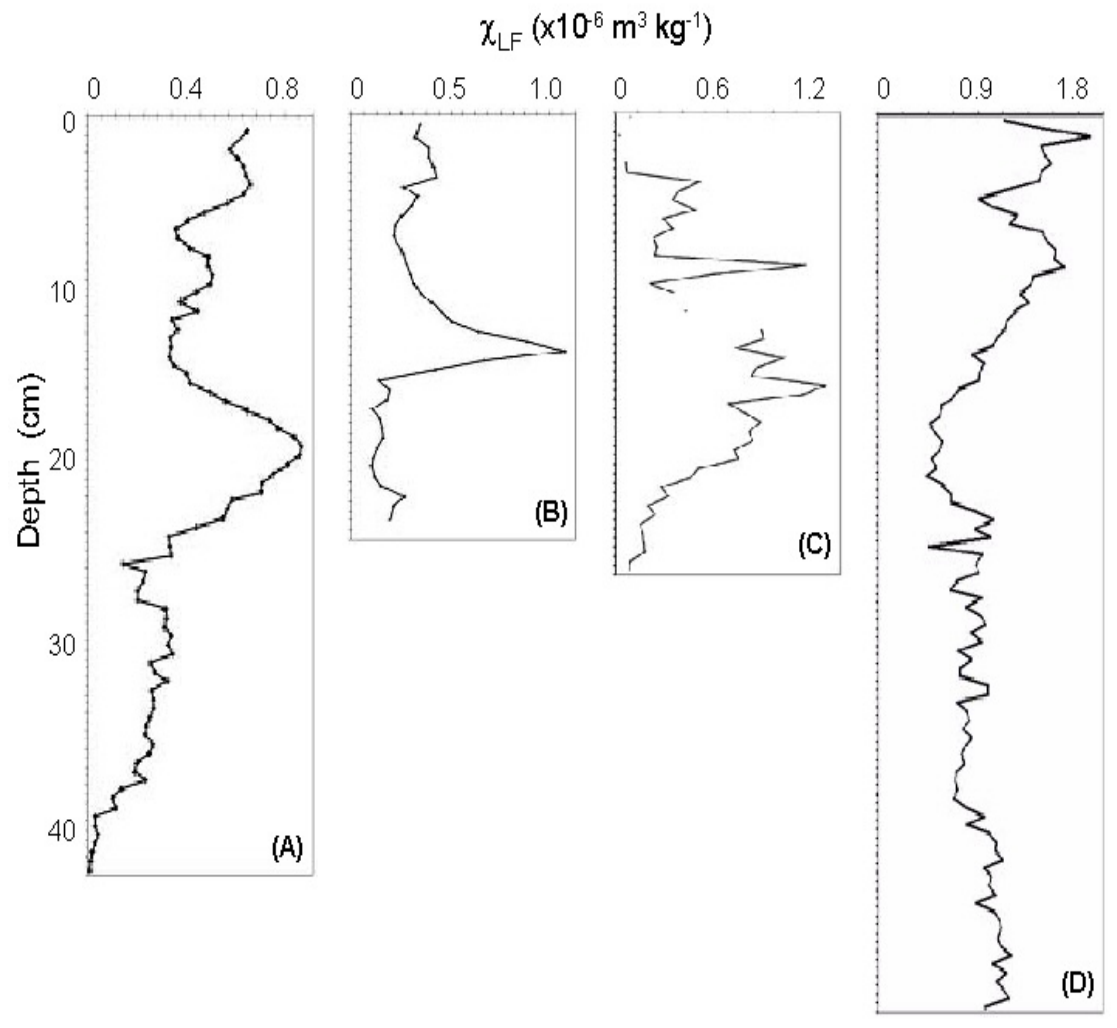

Figure 3: Magnetic susceptibility ( $\chi \mathrm{LF}$ ) profiles (A) Speke; (B) Dogs Kennel; (C) Windmill Hill; and (D) Daresbury Delph.

\section{Conclusions}

With careful site selection and sediment dating (i.e. Speke Hall Lake) a detailed, historical record for atmospheric pollution can be obtained from small urban lakes. Comparing profiles from several sites reveal notable local pollution events and, moreover, illustrate a distinctive regional signal at each of the sites investigated so far (plus superimposed site-specific events). The regional signal 
has several key features that can be characterised on the basis of their magnetic signature (supported by geochemical data, not presented), which can be related to known historical anthropogenic activities. In doing so, the work demonstrates that a regional profile is reproducible across South Merseyside and north Cheshire.

The research therefore highlights how it is possible to derive temporal records of atmospheric pollution which are location specific i.e. they produce detailed, high resolution records of changes in the nature and level of atmospheric pollution within a given area over time. Because the use of anthropogenic ponds or lakes from within an urban environment has been demonstrated, the propinquity and relevance of the archives become apparent. These records could potentially be used in conjunction with historical documented records for disease e.g. lung disease, in order to examine the temporal relationship (of $>200$ years) between records of air quality and public health. It therefore illustrates the potential for urban lake pollution stratigraphies to aid epidemiological studies and offer beneficial insights into how environments have changed; particularly for epidemiologists and public health scientists who want to explore and understand the relationships between human health and the environment over time.

\section{Acknowledgements}

This work forms part of the research development programme funded by Edge Hill University College and the National Health Service (Halton Primary Care Trust). All authors would like to thank Halton Primary Care Trust for their generous support and Mrs Ann Chapman (Edge Hill) for her time and map work. Thanks are also extended to Mr P. Oldfield of Halton Borough Council for his assistance with site identification.

\section{References}

[1] McCally, M., Life support: the environment and human health. MIT Press, Cambridge, 2002

[2] Brunekreef, B. \& Holgate, S.T., Air pollution and health. The Lancet, 360, N0.9341, pp 1233-1255, 2002.

[3] Gulland, A., Air pollution responsible for 600000 premature deaths worldwide, British medical Journal, 325, pp 1380-1381, 2002.

[4] Shilton, V.F., Booth, C.A., Smith, J.P., Giess, P., Mitchell, D.J. \& Williams C.D., Magnetic properties of urban street dusts and their relationship with organic matter content in the West Midlands, UK. Atmospheric Environment, (in press), 2005.

[5] Oldfield, F., Lakes and their drainage basins as units of sediment-based ecological study. Progress in Physical Geography, 1, pp. 460-504, 1977.

[6] Dearing, J.A., Holocene environmental changes from magnetic proxies in lake sediments. In: Maher, B.A. \& Thompson, R. (eds) Quaternary 
Climates, Environments and Magnetism. Cambridge University Press, 200.

[7] Von Gunten, H.R., Sturm, M. \& Moser, R.N., 200-year record of metals in lake sediments and natural background concentrations. Environmental Science \& Technology, 31, pp. 2193-2198, 1997.

[8] Edwards, K.J. \& Whittington, G., Lake sediments, erosion and landscape change during the Holocene in Britain and Ireland. Catena, 42, pp. 143$173,2001$.

[9] Lindstrom, M., Urban land uses influences on heavy metal fluxes and surface sediment concentrations of small lakes. Water, Air \& Soil Pollution, 126, pp. 363-383, 2001.

[10] Dearing, J.A., Boyle, J.F., Appleby, P.G., Mackay, A. \& Flower, R.J., Magnetic properties of recent lake sediments in Lake Baikal, Siberia. Journal of Palaeolimnology, 20, pp. 163-173, 1998.

[11] Jones, A.D., Industry \& Runcorn 1750 to 1960 . Publicity \& Information services Department, Halton Borough Council. January 1969.

[12] Stobart, J., The spatial organisation of a regional economy: central places in North-West England in the early $18^{\text {th }}$ century, Journal of Historical Geography, 22, 2, pp 147-158, 1996.

[13] Lawton, R. \& Pooley, C., Britain 1740-1950: An Historical Geography, London, Routledge, 1992.

[14] Trinder, B., The making of the industrial landscape, Dent, 1982.

[15] Szneter, S. \& Mooney, G., Urbanisation, mortality and the standard of living debate: new estimates of the expectations of life at birth in nineteenth century British cities, Economic History Review, 51, pp 84$112,1998$.

[16] Allen, J.F., Journal of the Society of Chemical Industry. $29^{\text {th }}$ June 1881

[17] Nicolson, S., Farming at Speke Hall 1066-1795. Liverpool, Merseyside Archaeological Society, 1983.

[18] Warren, K., Chemical Foundations: The Alkali Industry in Britain to 1926. Clarendon Press, Oxford, 1980.

[19] Sherard, R.H. (1898) The White Slaves of England: being true pictures of certain social conditions in the Kingdom of England in the year 1897. James Bowden, London.

[20] Royal Commission on Noxious Vapours, Report of the Royal Commission on Noxious Vapours, 1878.

[21] Chester City Council, A Review of Pollution 1986 to 1990. The Cheshire District Councils, pp. 68-82, 1991.

[22] Vidal, J., Toxic Shock, The Guardian - Newspaper, $11^{\text {th }}$ February 2000.

[23] Walden, J., Oldfield, F. \& Smith, J. (eds) Environmental Magnetism: a practical guide. QRA technical Guide No 5. London, 1999.

[24] Boyle, J., Rapid element analysis of sediment samples by isotope source XRF. Journal of Palaeolimnology, 23, pp. 213-221, 2000.

[25] Rose, N.L., Characterisation of carbonaceous particles from lake sediments, Hydrobiologia, 274, pp.127-132, 1994. 
[26] Appleby, P.G. \& Oldfield, F., The calculation of ${ }^{210} \mathrm{~Pb}$ dates assuming a constant rate of supply of unsupported ${ }^{210} \mathrm{~Pb}$ to the sediment. Catena, $\mathbf{5}$, pp. 228-233, 1978.

[27] Worsley, A.T., Booth, C.A., Power, A.L., Richardson, N., Appleby, P.G. and Wright, E.J., Atmospheric pollution and human health: the significance of a datable sedimentary archive from a small urban lake in Merseyside, UK., pp 199-208 in Environmental Health Risk III, edited by C.A. Brebbia, V. Popov \& D, Fayzieva, WIT Press, 2005.

[28] Power, A.L. Worsley, A.T., Booth, C.A. Richardson, N \& Bedford, A., The role of urban lake sediments as historical archives of industrial pollution and health linkages: an example from Daresbury Pond, North Cheshire, UK, pp 363-372 in Environmental Health Risk III, edited by C.A. Brebbia, V. Popov \& D, Fayzieva, WIT Press, 2005. 